\title{
ФРАНЦИЯ ПЕРЕД ВЫБОРАМИ В ЕВРОПАРЛАМЕНТ 2019 Г.
}

Аннотация. В статье рассматриваются причины глубокого сочиального кризиса, разразившегося в стране накануне выборов в Европарламент. Даётся характеристика избирательной кампании основных политических партий и обозначаются вероятные итоги выборов.

Ключевые слова: Франция, Э. Макрон, сочиальный кризис, выюборы, Европарламент, избирательная кампания.

Выборы в европейский парламент 2019 г. приобрели особое значение для нынешних французских властей в силу двух причин.

Первая. Убеждённый европеист, президент Э. Макрон исходит из того, что, будучи высокоразвитой страной средних масштабов, Франция может оставаться активным игроком на международной арене, только опираясь на совокупную мощь европейского центра силы. Вполне логично Макрон заявил, что будет противостоять евроскептицизму на континенте, а по сути выступать в той же роли, что и внутри страны на выборах 2017 г. - в роли своего рода волнореза, о который разбился поднимающийся популистский вал.

Пожалуй, большее значение имеет вторая причина - резкое изменение внутриполитической ситуации. После полутора лет энергичного проведения реформ команда молодого президента столкнулась с мощным, затянувшимся на четыре месяца протестным движением «жёлтых жилетов», в основе которого лежало популистское неприятие действующих властей, а расхожим стал лозунг «Макрона - в отставку». Движение выступало с разрозненными требованиями, среди которых выделялись два: повышение доходов населения, в первую очередь путём снижения налогов, и больший учёт мнений снизу при принятии государственных решений. Непрекращающиеся беспорядки притормозили продвижение реформ. Понятно, что Конституция Пятой республики надёжно гарантирует устойчивость президентской власти, но небывалые масштабы протеста во весь рост поставили вопрос о том, располагают ли власти достаточным ресурсом, чтобы продолжать реформистский курс. До вспыхнувшего социаль-но-политического кризиса евровыборы считались проходным замером общественного мнения. Теперь они приобретают характер проверки на прочность «эксперимента Макрона» - выживания сложившейся в стране в 2017 г. партийной конфигурации с господствующей центристской группировкой.

Вначале обескураженные силой протеста, в декабре 2018 г. власти попытались ответить на выраженные озабоченности. С одной стороны, приняты меры, нацеленные на повышение доходов наименее обеспеченных слоёв. Связанные с этим расходы, увеличив бюджетный дефицит, вынудили правительство отойти от линии на последовательное оздоровление государственных финансов. С другой, по инициативе президента запущены небывалые националь-

(C) Кудрявцев Андрей Константинович - кандидат экономических наук, старший научный сотрудник Центра европейских исследований НИ ИМЭМО им. Е.М. Примакова РАН. Адрес: 117997, Россия, Москва, ул. Профсоюзная, д. 23. E-mail: akud22@yandex.ru.

DOI: http://dx.doi.org/10.15211/vestnikieran220196672 
ные консультации по многим вопросам экономики и общественной жизни с тем, чтобы частично снять отчуждение людей от политической системы. В национальных дебатах, продолжавшихся более двух месяцев и закончившихся в середине марта, приняли участие около 1,5 млн человек, представители местных органов власти, члены правительства и глава государства. В настоящее время подводятся их итоги.

Несколько слов о причинах накопившегося недовольства, обернувшегося столь необычным социальным взрывом. Считается, что, как и в других развитых странах, в глубинной основе популизма, специфическим национальным проявлением которого выступают протесты «жёлтых жилетов», лежит размывание среднего класса под воздействием глобализации. Это, несомненно, так. Больше того, во Франции деиндустриализация, связанная с переносом производственных мощностей и рабочих мест в страны с более низкими издержками производства, протекала быстрее и зашла дальше, чем у её основных торговых партнёров.

Однако нельзя недооценивать ту роль, которую сыграл длительный сбой в процессе воспроизводства в ведущих капиталистических странах. Начало ему положил глубокий кризис 2008-2009 гг., открывший депрессивную полосу низких темпов экономического роста - во Франции они составляли около $1 \%$ ВВП в год. Медианный личный доход, т. е. доход, выше и ниже которого получает одинаковое число населения, после 2008 г. во Франции не рос, а доходы наименее обеспеченных групп несколько сократились ${ }^{1}$.

Впервые за 75 послевоенных лет прекратился ставший привычным прирост доходов населения, причём надолго - на 10 лет. Хотя статистика показывает незначительный рост располагаемых доходов населения, в нём нарастала доля принудительных затрат (налоги, сборы, страхование, квартплата и другие обязательных расходы), а свободных - снижалась, что воспринималось как ухудшение материального положения. Кризис обернулся массовой и, главное, застойной безработицей, по уровню которой Франция существенно превосходит многие страны Евросоюза. Тем самым обозначилась угроза утратить не только текущие доходы, но и социальный статус. Опасность деклассирования несёт с собой и временная занятость, резко расширившаяся за последние годы ${ }^{2}$.

Ещё один фактор накопления протестного потенциала - пространственный. В 1947 г. вышла в свет книга «Париж и французская пустыня», повествовавшая о гипертрофированном развитии столицы. С тех пор рост провинциальных городов, казалось бы, уравновесил рост Парижа. Но он привёл к формированию нового пространственного разлома: между десятком метрополий - крупными городскими агломерациями, с одной стороны, и провинцией, состоящей из средних, мелких городов, сельской местности, - с другой. Географы заговорили о трёх Франциях. Метрополиях, где компактно проживают квалифицированные специалисты, где быстрее средних показателей по стране растёт занятость, а ВВП на душу населения на 50\% выше, чем в других регионах. Пригороды, которые заполонили мигранты. Наконец, провинция, куда из метрополий, благодаря быстрому росту квартплаты, постепенно вытеснялись представители среднего класса. Между тем провинции присуща нехватка промышленной, торговой, культурной инфраструктуры и общественного транспорта, здесь менее доступны государственные услуги, а в отдельных районах из-за слабого присутствия врачей образовались «медицинские пустыни». И хотя во Франции есть примеры вполне удачных средних городов, именно «провинциалы», протестующие среди прочего против «территориальной сегрегации», составляли основную массу «жёлтых жилетов».

\footnotetext{
${ }_{2}^{1}$ G. de Calignong. Cette crise du pouvoir d'achat qui couvait depuis dix ans. Les Echos, 13.12.2018.

${ }^{2}$ A.Rodier, B.Bissuel.Dans la jungle des contrats courts. Le Monde, 24.03.2019.P. Breteau. Salariés précaires: comment les contrats courts ont été multipliés par quatre en trente ans. Le Monde, 06.02.2019.
} 
Свою роль в возникновении социального кризиса сыграли и действия нынешней администрации. К ним относится восприятие некоторых реформ Макрона как социально несправедливых ${ }^{3}$. У многих складывалось впечатление, что в начале своего президентского срока Макрон двигался в сторону отнюдь не скандинавской модели, как декларировалось в ходе предвыборной кампании, а скорее либерального капитализма англосаксонского толка.

Администрация Макрона развила необычно активную деятельность, чем подпитывала надежды на перемены к лучшему. О новой реформе объявлялось буквально каждую неделю, и в целом они велись фронтально и быстро. Но в стране накопилось столько проблем, что многие решения носили сугубо технический характер, а разъяснения, как сумма этих мелких подвижек вписывается в стратегический курс властей на модернизацию социально-экономической модели страны, не проводились. Поскольку в движении доходов и нормы безработицы серьёзных позитивных сдвигов не происходило, реформы воспринимались общественным мнением как безрезультатные. Со стороны властей практически отсутствовали объяснения, что требуется время, прежде чем структурные реформы дадут положительный результат. В этой обстановке вера в успех реформ, не приносящих быстрый эффект, покоилась только на доверии к их архитектору - президенту. Однако с середины 2018 г. в результате сначала инцидента с охранником президента, затем громких отставок двух ведущих министров правительства вопреки настояниям Макрона и, главное, неумелого управления социальным кризисом на его начальном этапе, это доверие снизилось.

Подспудно тлевшее неприятие власти неожиданно сосредоточилось на президенте лично. Стремясь укрепить вертикаль власти, Макрон брал на себя принятие многих решений. Как следствие, неубедительные промежуточные итоги государственной политики в сознании людей неразрывно срастались с фигурой президента. Серьёзный ущерб имиджу Макрона нанесли его неудачные жесты и публичные высказывания, давшие повод усматривать в его поведении пренебрежительность и высокомерие. Раздражение вызывало и то, что некоторым его выступлениям присуща усложнённая стилистика, а подчас они изобилуют англицизмами. Доходчивую для большинства французов форму выражения, отмечают наблюдатели, президенту ещё предстоит найти. Да он и сам накануне социального кризиса признавал, что ему не удалось примирить народ с его руководителями ${ }^{4}$.

Ещё незавершившийся социальный кризис на первый план вывел проблемы повышения жизненного уровня населения, социальной, в том числе налоговой справедливости, качества и доступности государственных услуг и экологии, что нашло отражение в содержании начавшейся избирательной кампании. Похоже, потрясения, произошедшие в политической системе страны по итогам выборов 2017 г. ещё не переварены. Среди них крах старых системных партий (социалистов и республиканцев), завоевание господствующих позиций центристской пропрезидентской группировкой, усиление радикальных образований, расположенных на обоих крайних флангах.

Сегодня многие политические движения не готовы выступить с обновлёнными доктринами и лозунгами. Отсюда (а не только из-за появившегося ограничения на совмещение различных избирательных мандатов) - выдвижение рядом партий молодых активистов во главе списка и стремление обкатать обновлённый кадровый состав. Не дали результатов попытки заключить избирательные союзы. В преддверии выборов обозначились две ведущие политические силы: не так давно созданная, а теперь правящая, партия президента «Вперёд, Респуб-

\footnotetext{
${ }_{4}^{3}$ A. Tonnelier. Les ultrariches, grands gagnants de la fiscalité Macron. Le Monde, 02.10.2018.

4 Emmanuel Macron: «Je n'ai pas réussi à réconcilier le peuple français avec ses dirigeants». Le Monde, le 14 novembre 2018.
}

Научно-аналитический вестник ИЕ РАН, 2019, №2 
лика!» и праворадикальное Национальное объединение (бывший Национальный фронт) под руководством М. Ле Пен. Избирательный список «Вперёд, Республика!» составлен таким образом, чтобы максимально широко захватить тяготеющего к центру избирателя. Его возглавила бывший министр по европейским делам, а вторую позицию согласился занять один из прошлых лидеров «зелёных». Камертоном для предвыборных установок послужила программная статья Макрона, недавно опубликованная во всех странах - членах Европейского союза. Принимая во внимание озабоченности «жёлтых жилетов», подчёркивается, что объединённая Европа «защищает» интересы трудящихся; продвигается заимствованная у правых идея пересмотра шенгенских соглашений и создание общих принципов предоставления убежища; поддерживается переход к единой социальной политике, чтобы положить конец социальному демпингу, создание европейского банка, который финансировал бы инвестиции в охрану окружающей среды и др.

Задача-максимум Национального объединения - превратить евровыборы в референдум против политики Макрона, имея в виду, что Ле Пен - единственный политический лидер, которая извлекла выгоды из падения популярности президента и к которой перешли лавры лидера оппозиции. Крайне правые ставят акцент на контроле за последствиями глобализации, выступая с лозунгом, что социально-экономический прогресс сегодня основывается на защите национальных интересов. Выход из еврозоны перестал быть для них приоритетом на том основании, что сегодня появились возможности менять Европу изнутри.

Бывшие системные партии не оправились после сокрушительного поражения 2017 г. Они зажаты в удушающих тисках между центристской президентской партией и радикальными движениями справа и слева, не говоря о последствиях расколов и отпочкований от них ряда ведущих представителей.

Социалисты рассчитывают мобилизовать левого избирателя, разочарованного Макроном. Учитывая общественные настроения, они подчёркивают, что экология и социальная справедливость должны идти рука об руку и противопоставляют себя правительству, решение которого повысить экологический налог на бензин послужило спусковым крючком для социального протеста «жёлтых жилетов». Чтобы продемонстрировать обновление, партия пошла на то, что её избирательный список возглавил непартийный левый интеллигент-публицист.

С низких стартовых позиций начинало кампанию крайне левое движение «Непокорённая Франция» Ж.-Л. Меланшона, популярность которого последние месяцы падала. «Непокорённая Франция» предлагает перезаключить европейские договоры, которые по рукам и ногам связывают национальную инициативу во многих областях. Вместе с тем, настаивают «непокорённые», «Фрексит» не является их программной установкой.

Развитие событий поместило в центр общественной дискуссии, казалось бы, левую тематику (покупательная способность, социальная справедливость и т.д.). Опросы дают внушительные $28 \%$ голосов за представителей левого спектра. Однако продолжающаяся «балканизация» сил, расположенных слева от Макрона, вряд ли позволит какой-либо из них воспользоваться благоприятным стечением обстоятельств. Менее 1 /3 голосов рассыпаны по пяти партийным спискам «непокорённые» $9 \%$, экологи 7,5\%, социалисты - 5,5\%, отколовшееся от социалистов движение Амона 3\% и ФКП 3\% 5 .

Республиканцы попытались нарастить свой политический вес, перехватывая некоторые идеи и риторику у правых радикалов и сосредоточившись на ужесточение контроля за иммиграцией, сохранении национальной идентичности и поддержании правопорядка внутри страны. Расчёт строился на том, что Макрон прочно захватил центр и проводит в жизнь многие

\footnotetext{
${ }^{5}$ A. Mestre. A Amiens, La France insoumise veut afficher son unite. Le Monde, 11.04.2019.

Научно-аналитический вестник ИЕ РАН, 2019, №2
} 
решения, которые долгое время отстаивали правоцентристы. Напротив, проигрыш Ле Пен на президентских выборах и обозначившиеся было противоречия в руководстве Национального объединения, полагали республиканцы, открывают для них дополнительные возможности. Расчёты оправдались лишь наполовину. Путь к центру, действительно, оказался перекрыт. Но развернувшееся протестное движение сообщило поступательный импульс крайне правым, которые на протяжении последнего десятилетия усиленно совершенствовали социальное измерение своих программ. Не случайно, опросы дают республиканцам всего 12-13\%.

Предстоящие выборы в Европарламент, скорее всего, закрепят серьёзные сдвиги, произошедшие в партийно-политической системе Франции. В прошлом правительственные партии утратили доверие избирателей, и перспективы их возрождения пока не просматриваются сколько-нибудь отчётливо. Крайне левые ставят задачу набрать $11 \%$ голосов, но даже если это удастся, достигнутый результат будет почти в два раза ниже результата Меланшона в первом туре президентских выборов.

Ныне по сути вновь воспроизводится ситуация второго тура президентских выборов, главный нерв которой составляло противостояние центристов и правых радикалов, которые и теперь будут бороться за первое место. Обычно для выборов в Европарламент характерна низкая явка и протестное голосование против действующей исполнительной власти. Разразившийся социальный кризис вполне мог бы усилить эти черты, на что делают ставку крайне правые. Вместе с тем, согласно опросам, меньше $1 / 4$ французов полагают, что кто-либо из сегодняшнего истеблишмента управлял бы страной лучше, чем действующий президент. Партия президента пытается представить дело так, что голосование за неё является полезным, поскольку сегодня только эта политическая сила способна остановить хаос, который неизбежно последует за продвижением национализма. В руках Макрона ещё одно оружие - подведение итогов национальных дебатов с итоговым выступлением в середине апреля и пошаговым обнародованием отдельных мер на протяжении всей избирательной кампании. Иначе говоря, в ходе предвыборной борьбы «возмущённому» народу будет регулярно сообщаться, что он услышан, а его требования принимаются во внимание - выверенный политтехнологичный ход. Выверенный, но обоюдоострый - всё будет зависеть от того, успокоят или разочаруют общественность предложенные властью решения. Согласно последним доступным опросам, за «Вперёд, Республика!» готовы отдать свой голос 22\%, а за Национальное объединение - 21,5\%.

Между тем, каковы бы ни были итоги выборов в Европарламент, Э. Макрон приближается ко второй половине своего президентского мандата в чрезвычайно сложной обстановке.

В ходе президентского пятилетия предполагалось решить две главные группы задач. Во-первых, перенастроить ряд подсистем, работающих со сбоями и недостаточно эффективно. Среди них: образование, рынок труда, система здравоохранения, а также органы законодательной власти и др. Во-вторых, провести антизатратные реформы, обеспечивающие расширение правительственных расходов заметно медленнее экономического роста, без ущерба для качества и доступности государственных услуг. Бюджетная «расчистка» высвобождала бы ресурсы для последующего наращивания вложений в науку и образование на новом витке научно-технической революции, нацеленной на повышение темпов потенциального роста, подточенного затянувшейся инвестиционной паузой и застойной безработицей последнего десятилетия. В сущности, к этому сводилась экономическая часть предвыборной программы Макрона, которую обозреватели считали, правда, чрезмерно осторожной. После прихода к власти она и проводилась в жизнь где-то удачно, где-то недостаточно решительно, но никогда и нигде революционно. И вдруг - мощный протестный взрыв, который резко обозначил, что предстоящие ресурсоэкономные реформы придётся проводить при более жёстких социальных ог-

Научно-аналитический вестник ИЕ РАН, 2019, №2 
раничениях, чем считалось ранее.

Добавим, что не подтвердились надежды на то, что Франция окончательно покинула зону невысоких темпов экономического роста, в которой оказалась после кризиса конца 2000-х гг. В обстановке ухудшившейся международной конъюнктуры считается, что в 2019-2022 гг. экономическая динамика Франции будет приближаться к темпам потенциального роста, оцениваемого в 1,3-1,5\% ВВП вместо ранее прогнозировавшийся 1,7\% ВВП в год.

В связи с этим, а также с учётом требований протестующих пришлось корректировать бюджетную стратегию до 2022 г. - до конца президентского срока. Обязательные изъятия (налоги и социальные взносы), которые предполагалось снизить на 1 процентный пункт (до 44,3\% ВВП), будут уменьшены до 43,8\% ВВП. Тем самым создаётся резерв под послабления, на которые может пойти правительство, принимая во внимание выказанную «жёлтыми жилетами» «налоговую аллергию». Дефицит бюджета сократится да 1,2\% ВВП вместо ранее намечавшегося выхода на почти сбалансированные правительственные счета. Естественно, что относительная величина государственного долга останется практически неизменной: вместо 5 п.п. она сократится на 1,5 п.П. - до 96,8\% ВВП ${ }^{6}$. Тем самым уязвимость государственных финансов по отношению к росту процентных ставок сохранится, а планировавшийся задел для наращивания инновационных расходов создан не будет.

Сегодня на первый план вышли три социально чувствительные реформы, затрагивающие интересы широких социальных групп: административная, пенсионная и совершенствование системы страхования по безработице. С их осуществлением связывались надежды на сокращение государственных расходов, по которым Франция (57\% ВВП) намного превышает средний показатель по странам, входящим в зону евро $(48,5 \% \text { ВВП })^{7}$. Ведь их снижение - непреложное условие повышения конкурентоспособности национальной экономики. Пока же властная команда так и не приступила к осуществлению предвыборного обещания Макрона сократить численность государственных чиновников на 120 тыс. человек, а также не представила общественности развёрнутый план ограничения правительственных затрат. Наибольшие резервы скрыты в недрах пенсионной системы. Пенсии по старости - самая значительная статья расходов совокупного правительства $(10,4 \%)$, и именно по этим затратам, выраженным в долях ВВП, Франция значительнее всего превосходит средние показатели своих основных европейских партнёров (превышение на $3,4 \%$ ВВП) ${ }^{8}$. Взрывоопасная тема повышения пенсионного возраста в связи с ростом продолжительности жизни время от времени вбрасывается в общественную дискуссию, но так и не легла на стол переговоров, которые многие месяцы ведутся правительством, профсоюзами и патронатом вокруг контуров пенсионной реформы. Посчитано, что увеличение возраста выхода на пенсию на один год обеспечивает ежегодную экономию примерно на 10 млрд евро. Не менее острое положение сложилось вокруг системы страхования по безработице, где патронат протестует против введения повышенных отчислений для предпринимателей, широко использующих временную занятость. Споры идут о методах экономии расходов и погашения накопленной задолженности.

Команде Макрона предстоит проводить в жизнь эти три болезненные реформы, именно когда и мировая конъюнктура и ужесточение социальных ограничений резко сузили их манёвренные возможности, что в принципе угрожает пагубно отразиться на их популярности. Но отложить реформы и некуда, да и нельзя, ибо Макрон пришёл к власти как президент перемен. Не поэтому ли главу государства часто сравнивают с велосипедистом, который не мо-

\footnotetext{
${ }_{7}^{6}$ M. Vignaud. Comment Les Républicains fustigent la stratégie budgétaire de Macron. Le Point, 10.04.2019.

${ }^{7}$ A. Feertchak. La France, championne européenne des dépenses publiques. Le Figaro, 03.06.2017.

${ }^{8}$ Où réduire le poids de la dépense publique ? Paris, Frace Straregie, janvier 2019.
} 
жет остановиться, чтобы не упасть? Между тем на него продолжают работать два защитных фактора. На политической сцене пока не появился лидер, способный стать надёжной альтернативой действующему президенту. С другой стороны, предстоящая избирательная консультация, скорее всего, выльется в противостояние крайне правых и центристской партии, выступающей в роли единственного противовеса радикалам всех мастей - «извечный второй тур» президентских выборов 2017 г, как иронизируют обозреватели. Постоянное тиражирование таких обстоятельств на руку президенту. Он считает себя надёжно защищённым «стеклянным потолком», когда в соответствии с принципом «республиканской дисциплины» избиратели, голосовавшие в первом туре за разные политические силы, во втором объединяют свои усилия, чтобы не допустить победы внесистемного радикала.

\section{Список литературы / References}

G. de Calignong. Cette crise du pouvoir d'achat qui couvait depuis dix ans. Les Echos, 13.12.2018.

A. Rodier, B. Bissuel. Dans la jungle des contrats courts. Le Monde, 24.03.2019.

P. Breteau. Salariés précaires: comment les contrats courts ont été multipliés par quatre en trente ans. Le Monde, 06.02.2019.

A. Tonnelier. Les ultrariches, grands gagnants de la fiscalité Macron. Le Monde, 02.10.2018.

Emmanuel Macron: «Je n'ai pas réussi à réconcilier le peuple français avec ses dirigeants». Le Monde, le 14 novembre 2018.

A. Mestre. A Amiens, La France insoumise veut afficher son unite. Le Monde, 11.04.2019.

M. Vignaud. Comment Les Républicains fustigent la stratégie budgétaire de Macron. Le Point, 10.04.2019.

A. Feertchak. La France, championne européenne des dépenses publiques. Le Figaro, 03.06.2017.

Où réduire le poids de la dépense publique ? Paris, France Straregie, janvier 2019.

\section{France before 2019 European Elections}

Author. Andrey Kudryavtsev, Candidate of Sciences (Economy), Senior Research Associate, Center for European Studies, Institute of World Economy and International Relations, Russian Academy of Sciences. Address: 23, Profsoyuznaya st., Moscow, Russia, 117997. E-mail: akud22@yandex.ru.

Abstract. The paper discusses the causes of the deep social crisis erupted in the country on the eve of 2019 European Elections. The electoral campaign of main political parties is examined and the possible results of elections are indicated.

Key words. France, Macron, social crisis, european elections, electoral campaign.

DOI: http://dx.doi.org/10.15211/vestnikieran220196672 